\section{Interactions of Irradiance Level and Iron Chelate Source During Shoot Tip Culture of Carica papaya $\mathrm{L}$.}

\author{
B. Castillo ${ }^{1}$, M.A.L. Smith ${ }^{2}$, and D.L. Madhavi ${ }^{3}$ \\ Department of Natural Resources and Environmental Sciences, University of \\ Illinois, Urbana, IL 61801-4778
}

\author{
U.L. Yadava ${ }^{4}$ \\ Department of Plant Sciences, Georgia Agricultural Experiment Station, Fort \\ Valley State University, Fort Valley, GA 31030-3298
}

Additional index words. chlorosis, establishment, proliferation, papaya, propagation

\begin{abstract}
Interactions between irradiance levels $\left(5-40 \mu \mathrm{mol} \cdot \mathrm{m}^{-2} \cdot \mathrm{s}^{-1}\right)$ and iron chelate sources (FeEDTA and FeEDDHA) were observed for Carica papaya shoot tip cultures during both the establishment and proliferation stages of microculture. Reduced levels of irradiance $\left(5 \mu \mathrm{mol} \cdot \mathrm{m}^{-2} \cdot \mathrm{s}^{-1}\right)$ favored shoot tip establishment regardless of the source or level of iron. However, the highest percentage of successful explant establishment (100\%), and significantly greater leaf length $(1.16 \mathrm{~cm}$; over double the size attained in any other treatment), resulted when a low concentration of FeEDTA alone was used at low irradiance. During the subsequent shoot proliferation stage, however, higher irradiance levels (30 and $40 \mu \mathrm{mol} \cdot \mathrm{m}^{-2} \cdot \mathrm{s}^{-1}$ ) were required, and FeEDTA failed to support culture growth when used as the sole iron source. The highest multiplication rates ( 3.6 shoots per explant) and leaf chlorophyll concentrations $(0.22 \mathrm{mg} / \mathrm{g}$ fresh mass $)$, and significantly improved shoot quality were achieved at $30 \mu \mathrm{mol} \cdot \mathrm{m}^{-2} \cdot \mathrm{s}^{-1}$ irradiance when both iron chelate formulations were combined (each at a $100 \mu \mathrm{M}$ concentration) in the proliferation medium. Chemical names used: benzylamino purine (BA); ferric disodium ethylenediamine tetraacetate or $\mathrm{FeNa}_{2}$ EDTA (FeEDTA); ferric monosodium ethylenediamine di(ohydroxyphenylacetate), (FeNaEDDHA) or Sequestrene 138Fe (FeEDDHA); indoleacetic acid (IAA); 1-naphthaleneacetic acid (NAA).
\end{abstract}

Papaya (Carica papaya L.) is a principal horticultural crop of tropical and subtropical regions, and is grown both as a fruit and as a good source of papain, a commercially valuable proteolytic enzyme (Dunne and Horgan, 1992). The fruit, stem, leaves, and roots of papaya are used in a wide range of medical applications, and the extracted papain enzyme has been used as a meat tenderizer and in the leather, wool, rayon, and beer industries (Ockerman et al., 1993; Osato et al., 1993; Purina and Sandhya, 1988). Papaya has been micropropagated (De Winnaar, 1988; Fitch, 1993; Litz and Conover, 1981); however, chlorosis has been a limitation during in vitro shoot culture. De Winnaar (1988) reported that $89 \%$ of established papaya plants were chlorotic after $30 \mathrm{~d}$ of culture in MS media (Murashige

Received for publication 10 Oct. 1996. Accepted for publication 14 Feb. 1997. This work was supported in part by the CSREES, USDA, under Agreement No. 93-38814-8709. We sincerely thank Andrès Guerrero, Biometry Group, Crop Sciences Department, Univ. of Illinois College of ACES, for statistical analysis. The cost of publishing this paper was defrayed in part by the payment of page charges. Under postal regulations, this paper therefore must be hereby marked advertisement solely to indicate this fact.

${ }^{1}$ Graduate Research Assistant.

${ }^{2}$ Professor of Plant Physiology; to whom reprint requests should be addressed.

${ }^{3}$ Visiting Assistant Professor.

${ }^{4}$ Professor of Horticulture.

1120 of papaya microculture, in an effort to minimize chlorosis and develop a protocol for routine maintenance of healthy microplants.

\section{Materials and Methods}

Plant material. Seeds from the self-pollinated hermaphroditic papaya cultivar Solo were shallowly planted in 6-cm containers filled with a mixture of 50 peat : 50 vermiculite $(\mathrm{v} / \mathrm{v})$, and covered with a $0.5-\mathrm{cm}$ layer of vermiculite. In the greenhouse, a transparent dome was placed over each container until germination occurred to maintain air temperatures of approximately $27{ }^{\circ} \mathrm{C}$ and over $90 \%$ relative humity $(\mathrm{RH})$. Seeds began to germinate in $\approx 15 \mathrm{~d}$. Plants grew rapidly and exhibited chlorotic symptoms within 1 week of germination. To obtain uniform healthy explants, a 100-ppm solution of soluble fertilizer (Peters 20-20-20) was applied to the soil surface and as a foliar drench 1 week prior to harvest of shoot tips. The greenhouse was maintained with day/night temperatures of 28/ $24 \pm 2{ }^{\circ} \mathrm{C}$, RH $80 \%$ to $90 \%$, with natural daylight $(12 \mathrm{~h})$ providing $\approx 500 \mu \mathrm{mol} \cdot \mathrm{m}^{-2} \cdot \mathrm{s}^{-1}$ irradiance at the soil surface.

Shoot tips $(3 \mathrm{~cm})$ were excised from $15-\mathrm{d}$ old seedlings $30 \mathrm{~d}$ after initial seed planting. Shoot tips were surface disinfested by rinsing in running water and washing in a solution of mild liquid detergent for $2 \mathrm{~min}$, then immersing and agitating in a solution of $5.25 \%$ sodium hypochlorite and two drops of Tween-20 (polyoxyethylene sorbitan monolaurate; Sigma, St. Louis), for $10 \mathrm{~min}$. Shoot tips were rinsed three times in sterile distilled water, and placed on the surface of 15 $\mathrm{mL}$ of medium contained in $25 \times 150-\mathrm{mm}$ culture tubes capped with 2-way caps (Magenta Corp, Chicago, Ill).

Media and culture conditions. The establishment stage refers to the initial culture period ( 5 weeks) during which explants initiated growth and adapted to culture. The proliferation phase refers to the subsequent 6 weeks and beyond, after subculture of shoot tips from the initial cultures, and during uniform shoot culture growth and maintenance of microplants in the same culture environment. Shoot cultures (except those harvested for fresh mass and chlorophyll analysis) were maintained continuously after the initial proliferation phase by subculture of $1.0-\mathrm{cm}$ shoot tips at 6 -week intervals. The basal medium for both phases contained MS basal salts (Murashige and Skoog, 1962), 3\% (w/v) sucrose, $2.22 \mu \mathrm{M} \mathrm{BA}$, $0.54 \mu \mathrm{MNAA}$, and $0.7 \%$ (mass/v) agar(Sigma). Treatments varied in the concentrations and formulation of iron (Table 1). Medium $\mathrm{pH}$ was adjusted to 5.8 before autoclaving. Cultures were incubated at each of three continuous irradiance levels: 5,30 , or $40 \mu \mathrm{mol} \cdot \mathrm{m}^{-2} \cdot \mathrm{s}^{-1}$ provided by cool-white fluorescent lamps, during both the establishment and proliferation stages. Culture room ventilation was sufficient to maintain temperature at $27 \pm 1^{\circ} \mathrm{C}$ in all treatments. Different irradiance levels were established by varying the density of lamps on individual culture shelves, and irradiance was monitored by placing the light sensor on a tray 
containing culture tubes at about the level of the medium/headspace interface.

Experimental design. A completely randomized design (CRD) was used. Two factors were considered: irradiance level and iron complement in the medium. Each unique treatment (iron source and concentration/irradiance level) was represented by 16 culture tubes, with one explant per tube, at both the establishment and proliferation stages, and the experiment was repeated. Measurements were taken from five replicates per treatment for number of shoots per explant, leaf length, and shoot height after the establishment phase (5 weeks), and again 6 weeks after subculture to the proliferation phase. After 6 weeks of the proliferation phase, fresh mass was also recorded, and the incidence of foliar chlorosis was noted. To quantify the degree of foliar chlorosis between treatments in the proliferation phase, visual evaluation was followed by chlorophyll analysis (Harborne, 1973). The excised leaves from four individual cultures were combined as the experimental unit (replicate) for chlorophyll extraction in acetone (four replicates per treatment). Chlorophyll content was determined spectrophotometrically using 663 and 645 wavelengths on a Beckman D-65 spectrophotometer. Data were analyzed by analysis of variance (ANOVA) using the SAS program version 6.11 (SAS Institute, Cary, N.C.).

\section{Results and Discussion}

The ANOVA for all accumulated data on leaf length, number of shoots per explant, and leaf chlorophyll content showed significant differences between irradiance levels and iron complements $(P \leq 0.0001)$, as well as significant interaction between iron and irradiance $(P \leq 0.0001)$. Effects of iron and irradiance were not purely additive, hence differences in culture performance were due to the joint effect of both factors. This interaction pattern occurred in both the establishment and proliferation stages (Schlotzhauer and Littell, 1987).

Establishment phase. Low irradiance (5 $\left.\mu \mathrm{mol} \cdot \mathrm{m}^{-2} \cdot \mathrm{s}^{-1}\right)$ resulted in the highest percentage of successful explant establishment when FeEDTA was present, as the sole source of iron, at $100 \mu \mathrm{M}$ (Table 1). Shoots were well developed, exhibited good green coloration, and attained the largest size in this treatment (Fig. 1). The average length of individual leaf blades (not including the petiole) was 1.16 $\mathrm{cm}$, which was more than twice the length of leaves in any of the other iron treatments under low irradiance (Fig. 2). The presence of FeEDDHA alone or in combination with FeEDTA resulted in lower percentage of survival, and severe stunting of most surviving shoots, at the lowest irradiance level (Table 1, Fig. 1). No losses due to explant contamination occurred in any of the iron/irradiance treatments, and low irradiance improved culture establishment, regardless of iron treatment. In the higher irradiance treatments (30 and $\left.40 \mu \mathrm{mol} \cdot \mathrm{m}^{-2} \cdot \mathrm{s}^{-1}\right)$, the percentage of successful culture establishment declined severely (Table 1), and surviving plantlets in all treat- ments were chlorotic with comparatively smaller leaves.

Proliferation phase. Higher levels of irradiance were required to support shoot growth during the proliferation stage than during establishment. Transfer of shoot tips to a me-

Table 1. Percentage of establishment of Carica papaya shoot tipsin vitrc regimes.

\begin{tabular}{|c|c|c|c|c|c|}
\hline \multirow[b]{3}{*}{ Medium } & \multirow{2}{*}{\multicolumn{2}{|c|}{$\begin{array}{c}\text { Iron source } \\
\text { and concn }(\mu \mathrm{M})\end{array}$}} & \multirow{2}{*}{\multicolumn{3}{|c|}{$\begin{array}{c}\text { Establishment }(\%) \\
\text { Irradiance level }\left(\mu \mathrm{mol} \cdot \mathrm{m}^{-2} \cdot \mathrm{s}^{-1}\right)\end{array}$}} \\
\hline & & & & & \\
\hline & FeEDTA & FeEDDHA & 5 & 30 & 40 \\
\hline 1 & 100 & $\cdots$ & 100 & 69 & 60 \\
\hline 2 & 200 & -- & 88 & 56 & 50 \\
\hline 3 & -- & 200 & 38 & 31 & 19 \\
\hline 4 & 100 & 100 & 31 & 19 & 13 \\
\hline 5 & 100 & 200 & 19 & 13 & 0 \\
\hline 6 & 200 & 100 & 38 & 6 & 0 \\
\hline
\end{tabular}

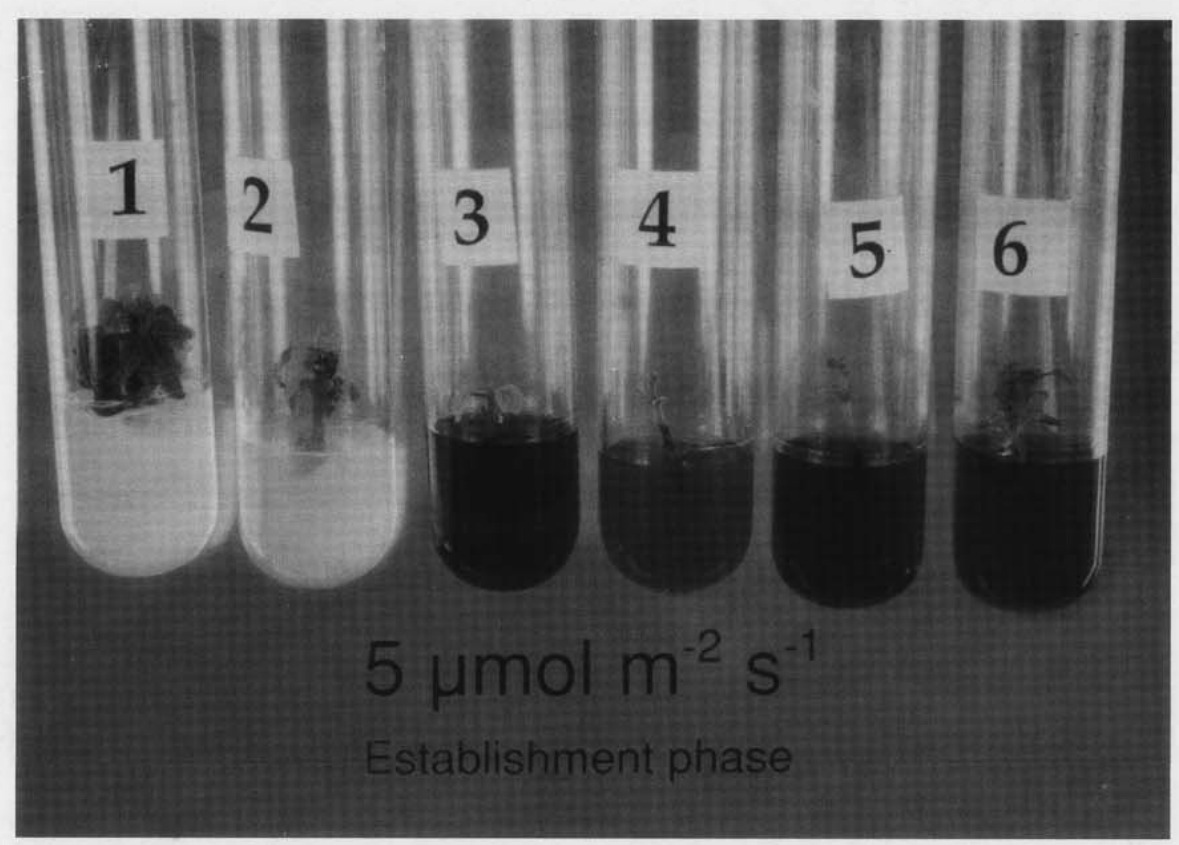

Fig. 1. Influence of medium iron source and concentration on Carica papaya microshoots durıng the establishment phase of in vitro culture, under a low irradiance regime $\left(5 \mu \mathrm{mol} \cdot \mathrm{m}^{-2} \cdot \mathrm{s}^{-1}\right)$. See Table 1 for contents of media.

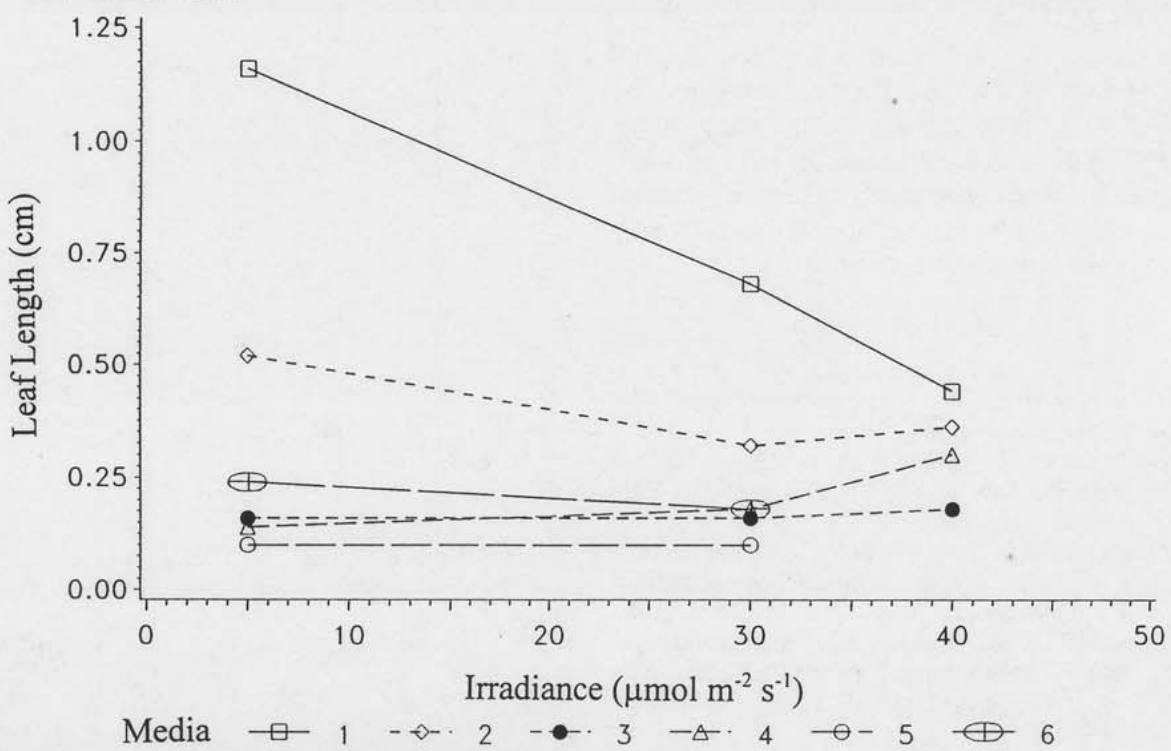

Fig. 2. Effects of irradiance level and medium iron complement on leaf length during the establishment phase for Carica papaya in vitro. See Table 1 for contents of media. F values for medium, irradiance, and their interaction were $99.36,23.70$, and 12.61 , respectively, all significant at $P \leq 0.0001$. 
growth (shoot number and size) was severely inhibited. Although FeEDTA as the sole source of iron provided adequate support during culture establishment, the presence of FeEDDHA was required for maximum chlorophyll development and shoot growth during proliferation (Fig. 4). Leaf chlorophyll content reached a maximum in medium 4 at $30 \mu \mathrm{mol} \cdot \mathrm{m}^{-2} \cdot \mathrm{s}^{-1}$ irradiance. Normal green leaves, without chlorosis, were consistently maintained in medium 4, which supported higher chlorophyll levels regardless of irradiance level. The lowest chlorophyll content (related to high incidence of chlorosis) was found in treatments which had only FeEDTA as the source of iron (Fig. 5).

The significant interactive effects of iron and irradiance level observed on papaya shoot culture performance clearly suggest that a change in medium is required between the initial establishment of explants (from the greenhouse or field) and the later proliferation and maintenance of shoot cultures. FeEDTA is arguably the most common iron chelate used in plant tissue culture, and some plants are not adversely affected even by a dramatic loss of soluble medium iron during light exposure. Papathanasiou et al. (1996) observed a drop in medium iron concentration from $4 \mathrm{mg} \cdot \mathrm{L}^{-1}$ to $0.1 \mathrm{mg} \cdot \mathrm{L}^{-1}$ in only 4 weeks at a $100 \mu \mathrm{mol} \cdot \mathrm{m}^{-2} \cdot \mathrm{s}^{-1}$ irradiance, without adverse influence on potato plantlet growth. However, papaya is particularly sensitive during shoot proliferation, even at the relatively low irradiance of 30 or 40 $\mu \mathrm{mol} \cdot \mathrm{m}^{-2} \cdot \mathrm{s}^{-1}$. The significant nonadditive effects of iron source/concentration and irradiance also illustrate that a combination of both iron chelates is necessary to support maximum shoot performance. Micropropagated rose shoots also maintained higher chlorophyll levels during routine maintenance when FeEDDHA replaced FeEDTA as the iron source (Van der Salm et al., 1994); however, neither interaction between chelate sources or irradiance levels were tested. In our tests, the synergy between the two iron chelate sources was superior to either source alone at any of the tested concentrations. If preformulated medium salts are purchased for production, a 100 $\mu \mathrm{M}$ concentration of iron (provided by FeEDTA) may already be included in the formulation. Supplementation with an additional $100 \mu \mathrm{M}$ concentration of iron provided by FeEDDHA may be sufficient to markedly improve culture performance.

\section{Literature Cited}

Barton, L.L. and B.C. Hemming. 1993. Iron chelation in plants and soil microorganisms. Academic, San Diego. p. 80-84.

De Winnaar, W. 1988. Clonal propagation of papaya in vitro. Plant Cell Tissue Organ Cult. 12:305-310.

Dunne, J. and L. Horgan. 1992. Meat tenderizers, p. 1745-1751. In: Y.H. Hui (ed.). Encyclopedia of Food Sci. and Tech. vol. 3. Wiley, New York.

Fitch, M.M. 1993. High frequency somatic embryogenesis and plant regeneration from papaya hypocotyl callus. Plant Cell Tissue Organ Cult. 32:205-212.

Hangarter, R. and T.C. Stasinopoulos. 1991a. Effect of Fe-catalyzed photooxidation of EDTA on root growth in plant culture media. Plant Physiol. 96:843-847.

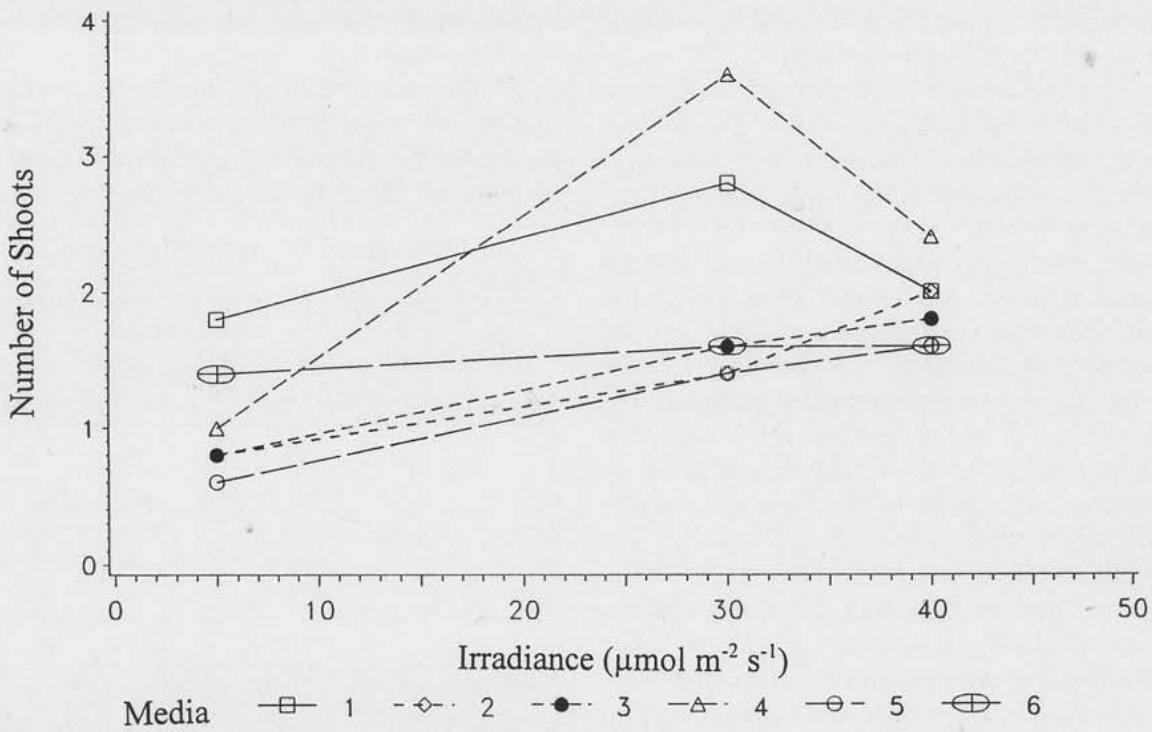

Fig. 3. Effects of irradiance level and medium iron complement on number of shoots after 6 weeks of the proliferation phase for Carica papaya in vitro. See Table 1 for contents of media. F values for medium, irradiance, and their interaction were $11.94,31.00$, and 4.26 , respectively, all significant at $P \leq 0.0001$.

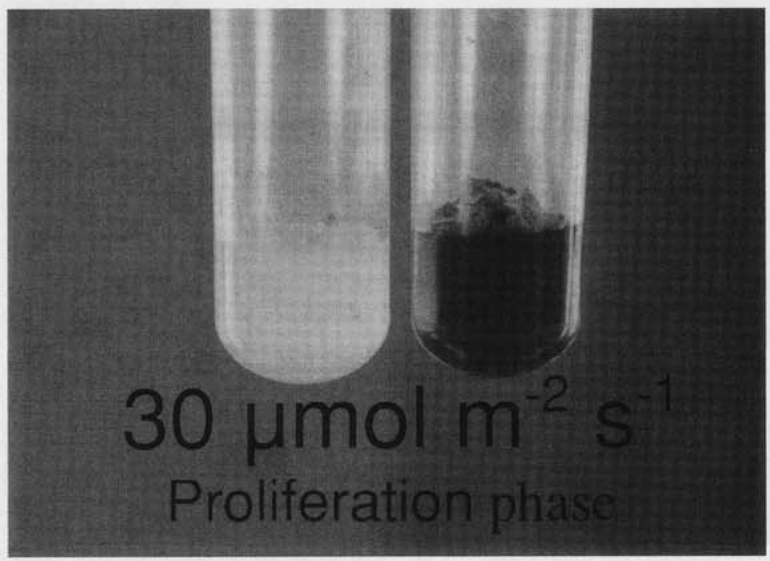

Fig. 4. Effect of iron complement on shoot development during the proliferation phase of in vitro growth for Carica papaya. Culture on the left contains $200 \mu \mathrm{M}$ iron as FeEDTA; culture on the right (darker medium) contains $200 \mu \mathrm{M}$ iron; $100 \mu \mathrm{M}$ as FeEDTA and $100 \mu \mathrm{M}$ as FeEDDHA.

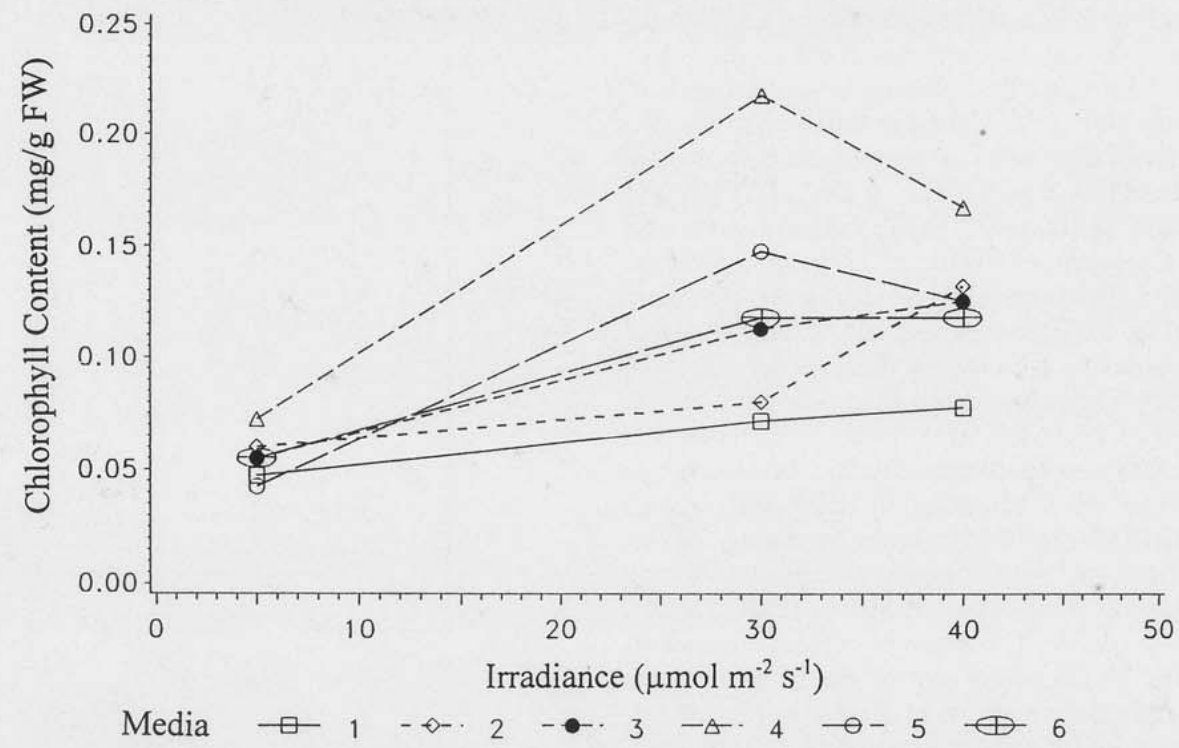

Fig. 5. Effects of irradiance and iron complement in the media on chlorophyll content of microcultured leaves after 6 weeks of the proliferation phase for Carica papaya. See Table 1 for contents of media. F values for medium, irradiance, and their interaction were $127.33,493.58$, and 34.59 , respectively, all significant at $P \leq 0.0001$. 
Hangarter, R. and T.C. Stasinopoulos. 1991b. Repression of plant tissue culture growth by light is caused by photochemical change in the culture medium. Plant Sci. 79:253-257.

Harborne, J.B. 1973. Phytochemical methods. Halsted Press, New York. p. 204-209.

Murashige, T. and F. Skoog. 1962. A revised medium for rapid growth and bioassays with tobacco tissue cultures. Physiol. Plant 15:473497.

Litz, R.E. and R.A. Conover. 1981. In vitro polyembryony in Carica papaya L. ovules. Z. Pflanzenphysiol. 104:285-288.

Ockerman, H.W., S. Harnsawas, and H. Yetim.
1993. Inhibition of papain in meat by potato protein or ascorbic acid. J. Food Sci. 58:12651268.

Osato, J.A., L. Santiago, G. Remo, M. Cuadra, and A. Mori. 1993. Antimicrobial and antioxidant activities of unripe papaya. Life Sci. 53:13831389.

Papathanasiou, F., C. Selby, and B. Harvey. 1996. Soluble iron is lost from MS medium pre-exposed to light but growth of potato plantlets is not inhibited. Plant Cell Tissue Organ Cult. 46:117-121.

Purina, A. and B. Sandhya. 1988. Genotypic differences of in vitro lateral bud establishment and shoot proliferation in papaya. Current Sci. 7:440442.

Schlotzhauer, S.D. and R.C. Littell. 1987. SAS system for elementary statistical analysis. SAS Inst., Cary, N.C.

Van der Salm, T.P., C.J. Van der Toorn, C.H. Cate, L.A.M. Dubois, D.P. DeVries, and H.J.M. Dons. 1994. Importance of the iron chelate formula for micropropagation of Rosa hybrida L. 'Moneyway'. Plant Cell Tissue Organ Cult. 37:73-77.

Yu, X. and B.M. Reed. 1993. Improved shoot multiplication of mature hazelnut (Corylus avellana L.) in vitro using glucose as a carbon source. Plant Cell Rpt. 12:256-259. 